\title{
Lessons from COVID-19 to Help Prevent Future Pandemics
}

\author{
Peter Daszak*
}

In just over 12 months since it was first discovered, coronavirus disease 2019 (COVID-19) has caused over 100 million confirmed cases and more than 2.2 million deaths. Its impact on our global economy has been staggering and likely to be in the tens of trillions of dollars by the time vaccines are fully deployed (1). COVID-19 has caused significant hardship, mortality, and morbidity across the world, from the lockdowns experienced by the citizens of Wuhan in early 2020, through to the waves of case spikes in European, North American, and other countries. Pandemics of this scale are rare, and many have called COVID-19 a once-in-acentury pandemic, but our research suggests that they are increasing in frequency, driven by a rise in the animal-to-human pathogen spillover events that usually cause them (2). Over the last 2 decades, our group has been tracking the origins of emerging diseases, analyzing their causes, plotting their geography, and mathematically dissecting the trends that drive them to emerge. Since 1960 alone, we have recorded over 500 emerging infectious disease (EID) "events" - the appearance of a new disease in the human population for the first time or the sudden rise in caseload of a known disease. By correcting for the underlying biases in reporting these events and testing their correlation with likely causes, we have shown that EIDs are on the rise and that there are predictable patterns in their emergence (3). Moreover, these patterns can be used to identify future pandemic risk, set up surveillance and control programs to reduce that risk, and build strategies to ultimately prevent pandemics.

The majority of EIDs, and almost all known pandemics, are caused by zoonotic pathogens, often viruses. They emerge from a large diversity of viruses carried by wildlife and livestock. They are transmitted on a daily basis across the vast human-livestock-wildlife interfaces associated with farming, the wildlife trade, deforestation, mining, road-building, and other activities that increase our contact with animals. This process of spillover is enhanced by our growing global population, our expanding ecological footprint, and our exponentially increasing travel and trade networks that allow diseases like COVID-19 to spread globally within days or weeks (4). Understanding these patterns, provides the elements of a prevention strategy.

The first step in any battle is to know your enemy, and in this case identify the size of the threat and where it's coming from. Given that viruses are the predominant group of pathogens and that most viral zoonoses are acquired from mammalian hosts, we repeatedly sampled two species of mammals (a fruit bat and primate) and conducted the same viral discovery protocol on each sample. Using data on the rate of discovery of new strains compared to repeat findings, we were able to estimate the unknown diversity of viruses in all mammal species - around 1.6 million unidentified viruses from all viral families that include zoonotic agents (5). We estimate that discovering $71 \%$ of these would cost around 1.2 billion USD over a 10 -year period and have called for the formation of a "Global Virome Project" to do this (6). We envisage countries working together to fund viral discovery programs that upload sequence data in almost realtime, so that it can be used to identify those microbes most likely to be able to cause zoonoses, and the data then can be used to block spillover and create vaccines. To help facilitate the work, we have analyzed every single known viral-animal host assemblage to estimate the global distribution of yet-to-be-discovered viruses in mammals and the host species most likely to harbor them $(7)$.

To win a battle, it takes a warrior who can think like their enemy and outwit them. The second step therefore is to think like a zoonotic virus. Viruses are particularly well adapted to zoonotic transfer, particularly those that commonly recombine or mutate more highly than others, like coronaviruses. Once viruses are able to cross the species barrier and spread in people, they rarely are constrained by national boundaries or differences in wealth or social status. Thus, the second step in preventing pandemics is to work together across the animal-livestock-human interface and block the pathways for transmission. This requires cross-sectoral collaboration that is difficult, 
rarely supported, and often funded by different silo'd mechanisms. In the USA, Europe, China, and many other countries that lead public health efforts, the ministries of agriculture, health, and environment compete for funding and authority. Using a One Health strategy that brings greater collaboration across these silo'd sectors may be a key way forwards. In a recent report on pandemics and the environment (8) and a policy paper aimed at the incoming US administration (9), we called for the formation of a high-level intergovernmental council on pandemic prevention and national One Health platforms to strengthen our preparedness. This approach could have direct impacts on reducing pandemic risk. One Health outbreak investigation teams could be formed to rapidly mobilize and investigate case clusters of unusual new illnesses to identify, or rule out, a zoonotic source. One Health policy strategies should be implemented to reduce the drivers of new emerging diseases (e.g. land use change, the wildlife trade, intensification of livestock production) or increase biosafety within these activities.

These programs will require resources, including trained staff and significant funding. However, they will rapidly pay for themselves: we estimate that the cost of programs to reduce deforestation and the wildlife trade to prevent pandemics will cost $10 \mathrm{~s}$ of billions of dollars, while the cost of pandemics is estimated at 500 million USD - 1 trillion USD each year $(8,10)$. Likewise, programs like the Global Virome Project or the World Bank One World One Health farm biosecurity initiative are likely to provide returns of at least an order of magnitude for each dollar spent over the long-term (11). Finally, the biggest lesson we can learn from COVID-19 is that pandemics exploit our weaknesses. While the pandemic raged, geopolitical forces have chipped away at global collaboration around science and public health. This is untenable if we are to defeat this enemy. Viruses see us as one species to move among and infect. To defeat them, we need global health cooperation more than ever.

doi: $10.46234 / \mathrm{ccdcw} 2021.035$

\# Corresponding author: Peter Daszak, daszak@ecohealthalliance.org.

Submitted: February 03, 2021; Accepted: February 05, 2021

\section{REFERENCES}

1. Cutler DM, Summers LH. The COVID-19 pandemic and the $\$ 16$ trillion virus. JAMA 2020;324(15):1495 - 6. http://dx.doi.org/10.1001/ jama.2020.19759.

2. Morse SS, Mazet JAK, Woolhouse M, Parrish CR, Carroll D, Karesh $\mathrm{VB}$, et al. Prediction and prevention of the next pandemic zoonosis. Lancet 2012;380(9857):1956 - 65. http://dx.doi.org/10.1016/S01406736(12)61684-5.

3. Allen T, Murray KA, Zambrana-Torrelio C, Morse SS, Rondinini C, Di Marco M, et al. Global hotspots and correlates of emerging zoonotic diseases. Nat Commun 2017;8(1):1124. http://dx.doi.org/10.1038/ s41467-017-00923-8.

4. Daszak P. Anatomy of a pandemic. Lancet 2012;380(9857):1883 - 4. http://dx.doi.org/10.1016/S0140-6736(12)61887-X.

5. Anthony SJ, Epstein JH, Murray KA, Navarrete-Macias I, ZambranaTorrelio CM, Solovyov A, et al. A strategy to estimate unknown viral diversity in mammals. mBio 2013;4(5): e00598-13. https://pubmed. ncbi.nlm.nih.gov/24003179/.

6. Carroll D, Daszak P, Wolfe ND, Gao GF, Morel CM, Morzaria S, et al. The global virome project. Science 2018;359(6378):872-4. http://dx.doi.org/10.1126/science.aap7463.

7. Olival KJ, Hosseini PR, Zambrana-Torrelio C, Ross N, Bogich TL, Daszak P. Host and viral traits predict zoonotic spillover from mammals. Nature 2017;546(7660):646-50. http://dx.doi.org/10. 1038/nature22975.

8. IPBES. Workshop report on biodiversity and pandemics by intergovernmental science-policy platform on biodiversity and ecosystem services. Bonn, Germany: IPBES. 2020. http://www.fao.org/ agroecology/database/detail/en/c/1364041/.

9. Daszak P, Keusch GT, Phelan AL, Johnson CK, Osterholm MT. Infectious disease threats: a rebound to resilience. Health Aff 2021;40(2):204 - 11. http://dx.doi.org/10.1377/hlthaff.2020.01544.

10. Dobson AP, Pimm SL, Hannah L, Kaufman L, Ahumada JA, Ando $\mathrm{AW}$, et al. Ecology and economics for pandemic prevention. Science 2020;369(6502):379 - 81. http://dx.doi.org/10.1126/science.abc3189.

11. Pike J, Bogich T, Elwood S, Finnoff DC, Daszak P. Economic optimization of a global stategy to reduce the pandemic threat. Proc Natl Acad Sci USA 2014;111(52):18519 - 23. http://dx.doi.org/10. 1073/pnas.1412661112.

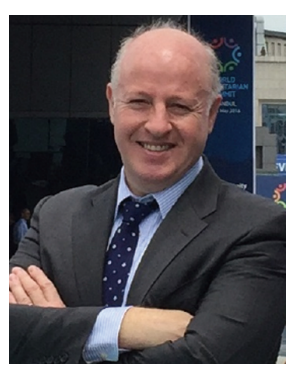

Peter Daszak, PhD

President, EcoHealth Alliance 